\title{
Kepatuhan di Tengah Kompleksitas Pajak: Apakah Literasi Memiliki Peran?
}

Christian Alessandro Noreen ${ }^{1}$, Ari Budi Kristanto ${ }^{2}$

DOI: https://doi.org/10.35838/jrap.2021.008.02.14

${ }^{1}$ Universitas Kristen Satya Wacana, Jawa Tengah, Salatiga

${ }^{2}$ Universitas Kristen Satya Wacana, Jawa Tengah, Salatiga

\section{ARTICLE INFO \\ JEL Classification: \\ H21; H25}

Key words:

tax, compliance, complexity, literacy.

\begin{abstract}
Tax regulations have become increasingly complex in recent years. Therefore, this study aims to determine whether the tax complexity can reduce tax compliance. Furthermore, this study also intends to find out whether public literacy can play a role in maintaining compliance despite experiencing complex taxation aspects. This study uses secondary data in the form of complexity scores, tax effort, and literacy scores of various countries around the world. The sample of this study amounted to 52 countries, which were obtained by the purposive sampling method. This research is a quantitative study using moderated regression analysis. This study found that tax complexity is proven to reduce tax compliance. However, literacy cannot weaken these negative effects. The results of this study imply that the government needs to consider the complexity of regulations and procedures for fulfilling tax obligations to increase tax revenues.
\end{abstract}

\begin{abstract}
ABSTRAK
Regulasi pajak semakin kompleks pada beberapa tahun terakhir. Oleh sebab itu, penelitian ini bertujuan untuk mengetahui apakah kompleksitas pajak dapat mengurangi kepatuhan pajak. Selain itu, penelitian ini juga bermaksud untuk mencari tahu apakah literasi masyarakat dapat berperan untuk mempertahankan kepatuhan meskipun mengalami aspek perpajakan yang kompleks. Studi ini menggunakan data sekunder berupa skor kompleksitas, tax effort, serta skor literasi berbagai negara di dunia. Adapun sampel penelitian ini berjumlah 52 negara, yang diperoleh dengan metode purposive sampling. Penelitian ini adalah studi kuantitatif dengan menggunakan analisis regresi dengan pemoderasi. Penelitian ini menemukan bahwa kompleksitas pajak terbukti dapat mengurangi kepatuhan pajak. Namun demikian, literasi tidak dapat memperlemah efek negatif tersebut. Hasil penelitian ini berimplikasi bahwa pemerintah perlu mempertimbangkan kompleksitas regulasi maupun tata cara pemenuhan kewajiban perpajakan untuk dapat meningkatkan pendapatan pajak.
\end{abstract}

\section{PENDAHULUAN}

Perubahan peraturan pajak terus terjadi di berbagai negara. Hal tersebut tidak lepas dari adanya pengaruh organisasi dunia global yang berfungsi sebagai konsultan dan mengkritisi regulasi pajak di dunia seperti Organisation for Economic Co-operation and Development (OECD) dan Base erosion and profit shifting (BEPS) (Hoppe, Schanz, et al., 2018). Perubahan yang terjadi mengakibatkan peraturan perpajakan bertambah kompleks. Hoppe et al. (2020) melakukan survey yang menghasilkan bahwa kompleksitas pajak meningkat pada 2 tahun terakhir di 59 negara dan regulasi yang paling kompleks di 70 negara adalah transfer pricing. Peningkatan kompleksitas pajak disebabkan oleh perubahan sistem perpajakan. Perubahan yang terjadi merupakan penyesuaian- 
penyesuaian dengan kondisi industri saat ini. Revolusi industri memberikan dorongan untuk mengembangkan teknologi dan juga mempengaruhi perubahan sistem pajak nasional maupun pajak internasional (Vishnevsky \& Chekina, 2018). Perkembangan teknologi produksi tersebut saling berhubungan dengan perpajakan serta memiliki hubungan interdependen.

Pajak yang semakin kompleks memiliki risiko yang dapat mengancam pendapatan pajak suatu negara. Pajak yang kompleks dapat menyebabkan kebingungan pada wajib pajak serta timbul upaya untuk melakukan penghindaran pajak (Budak \& James, 2018). Dampak kerugian dari penghindaran pajak di Uni Eropa diperkirakan sebesar 50 sampai 70 miliar Euro (Dover et al., 2015). Kompleksitas yang tinggi dapat menyebabkan ketidakpastian mengenai peraturan perpajakan dan mengakibatkan pertumbuhan ekonomi terhambat (Collier et al., 2018).

Kompleksitas pajak dapat berpengaruh terhadap berbagai aspek, salah satunya adalah pada kepatuhan wajib pajak. Penelitian yang dilakukan oleh Hamid et al. (2018) membahas mengenai faktor yang mempengaruhi kepatuhan pajak pada UMKM di Malaysia yang menghasilkan bahwa kompleksitas pajak berpengaruh positif pada kepatuhan pajak. Penelitian lain menghasilkan hubungan negatif antara kompleksitas dan kepatuhan pajak pada lingkup yang berbeda. Kompleksitas pajak yang tinggi menyebabkan kepatuhan yang rendah pada petani tebu di Zimbabwe (Sebelempofu \& Chinoda, 2019) dan di Kamboja dengan menggunakan theory of planned behaviour (Taing \& Chang, 2021). Berbeda dengan Alhempi et al. (2020) yang menemukan bahwa kompleksitas tidak mempengaruhi kepatuhan pajak pada wajib pajak orang pribadi untuk melaporkan pajak pendapatannya di Pekanbaru, Riau. Ketidakkonsistenan penelitian sebelumnya, menimbulkan dugaan bahwa ada variabel lain yang berperan dalam mempengaruhi hubungan antara kompleksitas pajak dan kepatuhan pajak.

Regulasi pajak yang terlalu kompleks membuat masyarakat sulit untuk informasi mengenai peraturan perapajakan yang berlaku. Penelitian yang menghubungkan pajak dengan literasi sebagai kemampuan untuk menyerap informasi sudah pernah dilakukan. Martinez dan da Silva (2019) menguji bagaimana pemahaman masyarakat di Brazil pada peraturan pajak berdasarkan tingkat kesulitan peraturan pajak untuk dipahami atau readability. Berdasarkan uraian diatas maka penelitian ini akan secara khusus mengakomodasi peran tingkat literasi dalam kepatuhan pajak. Dengan demikian, penelitian ini akan menggunakan tingkat literasi sebagai variabel moderasi.

Penelitian ini akan melihat pada level global sehingga mendapat pandangan secara luas tentang pengaruh antar variabel. Dengan demikian pertanyaan penelitian yang akan dijawab pada penelitian ini adalah apakah kompleksitas pajak mempengaruhi secara positif terhadap kepatuhan wajib pajak? Apakah tingkat literasi pada suatu negara dapat memperlemah pengaruh kompleksitas pajak pada kepatuhan pajak? Tujuan Penelitian ini adalah untuk mengetahui apakah kompleksitas pajak berpengaruh kepada kepatuhan pajak dan melihat apakah tingkat literasi wajib pajak dapat memperlemah pengaruh kompleksitas pajak pada kepatuhan pajak. Hasil penelitian ini diharapkan dapat membantu pemerintah dalam menentukan desain regulasi pajak serta memanfaatkan potensi masyarakat dalam hal tingkat literasi untuk mengupayakan kepatuhan pajak.

\section{TELAAH TEORI DAN PENGEMBANGAN HIPOTESIS}

\subsection{TELAAH TEORI}

\section{Kompleksitas Pajak}

Tran-Nam dan Evans (2014) mengartikan kompleksitas pajak sebagai kesulitan, waktu dan biaya dalam mengintrepretasi dan memenuhi regulasi pajak. Kompleksitas pajak dapat memberikan gambaran mengenai kesulitan dalam membaca, memahami, dan mematuhi peraturan pajak (Hoppe, Deborah, et al., 2018). Kompleksitas pajak disebabkan oleh 
beberapa faktor. Pertama, perubahan regulasi pajak sering terjadi. Kedua, diperlukan adanya perhitungan yang cukup rumit untuk memenuhi kewajiban perpajakan. Ketiga, regulasi yang detail seperti terlalu banyak peraturan, pengecualian, dan keterkaitan dengan peraturan lain. Keempat, dokumentasi yang lengkap dan harus disiapkan serta di disimpan untuk memenuhi kewajiban perpajakan. Kelima, formulir pajak yang rumit dan panjang untuk diisi. Keenam, tidak komprehensifnya regulasi pajak sehingga menyebabkan regulasi tidak jelas dan tepat serta timbul keambiguan. Terakhir, regulasi pajak tidak dapat diprediksi akan dijalankan secara tepat oleh pemerintah (Hoppe, Schanz, et al., 2018).

\section{Kepatuhan pajak}

Kepatuhan pajak dapat didefinisikan sebagai proses dimana wajib pajak melaporkan pajak terutang dengan nominal yang sesuai dan membayar sesuai kewajiban pajak menurut regulasi pajak yang berlaku (Palil \& Mustapha, 2011). Melaporkan pajak tepat waktu dan akurat serta membayar pajak tepat waktu merupakan indikator kepatuhan pajak (Hallsworth, 2014). Kepatuhan pajak juga dapat dilihat dari perbedaan nominal pajak terutang dengan pajak yang terbayar secara aktual (Kamleitner et al., 2012). Mawejje dan Sebudde (2019) melihat kepatuhan pajak dari realisasi pendapatan pajak dan potensi pendapatan pajak. Semakin rendah perbedaan antara realisasi pendapatan pajak dan potensi pendapatan pajak maka dapat dikategorikan sebagai patuh. Perbedaan tingkat potensi pendapatan pajak dan tingkat realisasi pendapatan pajak diartikan oleh Mascagni et al. (2018) sebagai gap kepatuhan.

Pendapatan pajak akan bertambah seiring dengan meningkatnya kepatuhan pajak. Semakin tinggi kepatuhan, risiko masyarakat untuk melakukan penghindaran pajak sehingga pendapatan pajak akan meningkat (Alm et al., 2019). Sebaliknya, jika kepatuhan pajak rendah pemerintah perlu mengeluarkan biaya untuk membuat kepatuhan pajak tinggi. Biaya yang diperlukan agar wajib pajak patuh pada regulasi pajak didefinisikan sebagai compliance cost (Lignier et al., 2012).

\section{Literasi}

Literasi merupakan kemampuan untuk menyerap informasi pada masyarakat suatu negara. Literasi bisa didefinisikan sebagai kemampuan untuk menemukan informasi secara efektif, merangkai berbagai informasi secara efektif, berpikir kritis mengenai sumber informasi, sera menyimpulkan berbagai informasi menjadi satu pengetahuan dasar (Swapna \& Biradar, 2017). Definisi lain untuk literasi menurut Montoya (2018) adalah kemampuan untuk mengidentifikasi, memahami, menginterpretasi, membuat, mengkomunikasikan, memperhitungkan, menggunakan materi tertulis yang diasosiasikan dengan bermacam-macam konteks

Dalam penelitian ini, tingkat literasi digunakan untuk melihat seberapa mampu masyarakat dalam suatu negara dalam membaca dan memahami regulasi perpajakan. Jika masyarakat mampu membaca regulasi pajak dengan baik, maka mereka dapat memahami dan memenuhi syarat-syarat perpajakan yang berlaku (Martinez \& da Silva, 2019). Tingkat literasi yang tinggi menurut Mutascu dan Danuletiu (2013) dapat meredam niat wajib pajak untuk melakukan penghindaran pajak dan tetap patuh pada regulasi pajak. Nichita et al. (2019) berpendapat bahwa semakin paham masyarakat terhadap regulasi pajak, maka kepatuhan pajak akan meningkat pula. Dampak akhirnya, pendapatan pajak dapat meningkat jika tingkat kepatuhan pajak tinggi.

\subsection{PENGEMBANGAN HIPOTESIS}

\section{Hubungan kompleksitas pajak dan kepatuhan pajak}

Kompleksitas pajak yang tinggi dapat berdampak langsung pada kepatuhan pajak (Remali et al., 2020). Semakin kompleks suatu regulasi perpajakan, maka wajib pajak semakin sulit untuk memahami regulasi pajak. Kesulitan dalam memahami peraturan pajak 
tersebut memunculkan risiko bahwa ada kemungkinan bahwa wajib pajak sulit untuk memenuhi kewajiban perpajakannya (Palil \& Rusyidi, 2013). Pemahaman mengenai regulasi pajak memiliki peran penting dalam meningkatkan kepatuhan pajak (Oladipupo \& Obazee, 2016). Sehingga, wajib pajak sulit untuk patuh pada regulasi perpajakan jika kompleksitas regulasi perpajakannya tinggi.

Semakin kompleks regulasi pajak pada suatu negara, dapat mengakibatkan kepatuhan pajak yang semakin rendah (Gambo et al., 2014; Martins \& Taborda, 2017; Remali et al., 2020). Isa (2014) mengatakan bahwa pajak yang sederhana merupakan kunci keberhasilan dalam meningkatkan kepatuhan pajak. Pajak yang sederhana memiliki pengaruh kuat pada kepatuhan pajak (Dwenger et al., 2014). Regulasi pajak yang sederhana akan meminimalisir ketidakpatuhan wajib pajak (Neve \& Imbert, 2019). Dengan uraian diatas, diduga regulasi pajak yang kompleks membuat wajib pajak sulit untuk patuh pada regulasi pajak. H1: Kompleksitas pajak berpengaruh negatif terhadap kepatuhan pajak.

\section{Tingkat literasi sebagai moderasi}

Pajak yang kompleks menuntut wajib pajak untuk lebih berusaha dalam memahami regulasi perpajakan. Untuk dapat memahami regulasi pajak, diperlukan kemampuan untuk menyerap informasi yang berkaitan dengan konteks pajak. Dengan adanya tingkat literasi yang tinggi, wajib pajak dapat lebih memahami regulasi perpajakan walaupun regulasi pajak tersebut kompleks. Wajib pajak yang paham, akan patuh pada regulasi pajak. Pemerintah perlu memperhatikan tingkat literasi sehingga kemampuan masyarakat untuk memahami informasi mengenai regulasi pajak meningkat dan dampak akhirnya adalah meningkatnya kepatuhan pajak.

Tingkat Literasi memberikan pengaruh dalam tingkat pemahaman masyarakat terhadap regulasi pajak (Martinez \& da Silva, 2019). Tingkat literasi digunakan sebagai dorongan untuk meningkatkan kepatuhan pajak (Gerger et al., 2019; Nichita, 2015). Dengan tingkat literasi yang tinggi, wajib pajak akan tetap patuh pada regulasi perpajakan meskipun regulasi yang diterapkan kompleks. Tingkat literasi memberi efek moderasi sehingga memperlemah pengaruh kompleksitas peraturan pajak pada kepatuhan pajak. H2 : Tingkat literasi memperlemah pengaruh kompleksitas pajak terhadap kepatuhan pajak.

\section{Rerangka Penelitian}

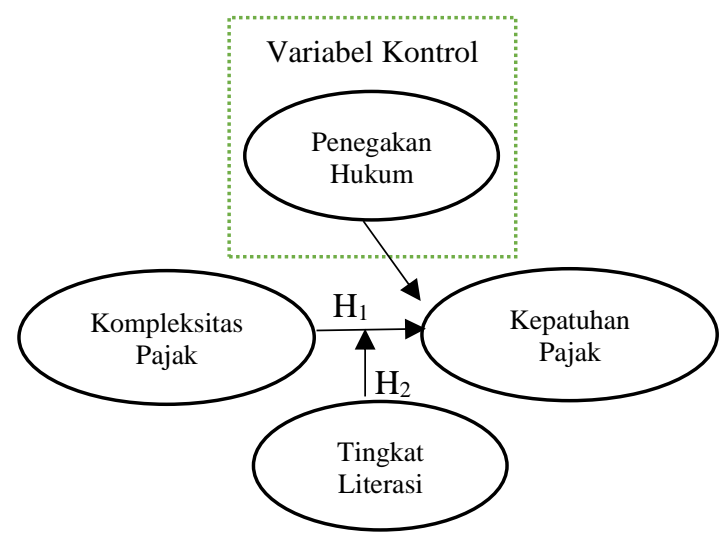

Tabel 1. Populasi dan Sampel

\begin{tabular}{lc}
\hline Jumlah negara di dunia (WorldoMeter, 2018) & 195 \\
\hline $\begin{array}{l}\text { Negara tidak terdaftar pada dataset (Hoppe, Deborah, et al., 2018; Mawejje \& } \\
\text { Sebudde, 2019; Roser \& Ortiz-Ospina, 2018; World Justice Project, 2020) }\end{array}$ & \\
\hline Sampel & 52 \\
\hline
\end{tabular}




\section{METODE PENELITIAN}

\section{Populasi dan sampel}

Populasi yang akan dipakai dalam penelitian ini adalah seluruh negara di dunia. Negara di dunia yang ada dalam data Persatuan Bangsa-Bangsa (PBB) terdapat 195 negara (WorldoMeter, 2018). Teknik pengambilan sampel yang digunakan adalah purposive sampling dengan negara yang terdapat pada data kepatuhan pajak (Mawejje \& Sebudde, 2019), kompleksitas pajak (Hoppe, Deborah, et al., 2018), tingkat literasi (Roser \& Ortiz-Ospina, 2018), rule of law index (World Justice Project, 2020). Data mengenai kepatuhan pajak yang disajikan oleh Mawejje dan Sebudde (2019) sebanyak 150 negara, lalu data mengenai indeks kompleksitas pajak sebanyak 109 negara (Hoppe, Deborah, et al., 2018), dan data mengenai tingkat literasi sebanyak 156 negara (Roser \& Ortiz-Ospina, 2018).

\section{Sumber data}

Data yang digunakan dalam penelitian ini adalah data sekunder yaitu tax effort untuk mengetahui kepatuhan pajak pada suatu negara yang diambil dari penelitian Mawejje dan Sebudde (2019). Indeks kompleksitas pajak dilihat melalui survey yang dilakukan pada konsultan pajak di berbagai negara mengenai kompleksitas pajak pada perusahaan multi nasional pada tahun 2018 (Hoppe, Deborah, et al., 2018). Tingkat literasi diperoleh dari ourworldindata.org yang disusun oleh Roser dan Ortiz-Ospina (2018) berdasarkan data dari UNESCO.

\section{Variabel tak bebas}

Kepatuhan pajak merupakan variabel tak bebas dalam penelitian ini. Kepatuhan pajak tercermin dari tax effort yang merupakan tingkat pemenuhan potensi pendapatan pajak yang dapat diterima dibandingkan dengan pendapatan pajak aktual yang diterima (Mawejje \& Sebudde, 2019). Terdapat selisih antara potensi dan aktual pendapatan pajak yang dapat mengindikasikan kepatuhan pajak pada suatu negara (Kamleitner et al., 2012). Data yang disusun oleh (Mawejje \& Sebudde, 2019) menggunakan Government Revenue Dataset (GRD) yang disusun oleh International Centre for Tax and Development (ICTD). GRD merupakan data yang dapat membandingkan pendapatan pajak antar negara. Data tersebut berisikan pendapatan pajak, potensi pendapatan pajak dan tax effort berbagai negara. Semakin tinggi persentase tax effort maka realisasi pendapatan pajak semakin mendekati potensi maksimalnya. Kecilnya gap antara realisasi dan potensi pendapatan pajak menandakan kepatuhan pajak yang tinggi. Sehingga penelitian ini menggunakan tax effort untuk mengukur kepatuhan pajak.

\section{Variabel Bebas}

Variabel bebas yang digunakan pada penelitian ini adalah kompleksitas pajak. Hoppe et al. (2020) melakukan survey pada 565 konsultan pajak dari 109 negara. Survey tersebut menghasilkan data berupa indeks kompleksitas pajak mengenai regulasi pajak pada perusahaan multinasional. Indeks tersebut dibuat berdasarkan tax code complexity dan tax framework complexity. Tax code complexity mendeskripsikan kesulitan dalam membaca, memahami, dan memenuhi regulasi pajak. Sementara tax framework complexity menjelaskan kompleksitas yang ada pada administrasi dan sistem perpajakan. Indeks kompleksitas pajak ini memiliki rentang dari 0 sampai 1. Semakin tinggi angka suatu negara, maka semakin tinggi juga kompleksitas pajaknya.

\section{Variabel Moderasi}

Tingkat literasi digunakan sebagai variabel moderasi. Data berupa tingkat literasi yang diperoleh dari ourworldindata.org. (Roser \& Ortiz-Ospina, 2018)_mengumpulkan data dari UNESCO berupa persentase orang dewasa yang dapat memahami, membaca dan menulis pernyataan sederhana dalam kehidupan sehari-hari. Rentang waktu yang terdapat dalam data tersebut sejak tahun 1975 sampai 2015. Data tingkat literasi ini sebelumnya 
sudah dipergunakan dalam penelitian terkait pajak oleh Whitmore (2020) yang mengukur kemampuan masyarakat memahami pengenaan pajak dalam produk yang dikonsumsi.

\section{Teknik Analisis Data}

Teknik analisis data yang digunakan dalam penelitian ini adalah Moderated Regression Analysis (MRA). MRA merupakan salah satu cara analisis untuk menguji interaksi dengan tambahan variabel moderasi. Menggunakan MRA, penelitian ini akan menguji hubungan antara kompleksitas pajak dengan kepatuhan pajak serta memperhitungkan tingkat literasi sebagai variabel moderasi.

\section{Tahapan analisis data}

Setelah proses pengumpulan data, akan dilakukan langkah statistik deskriptif berupa jumlah data, nilai minimal, nilai maximal, ratarata, dan standar deviasi. Setelah itu dilakukan pengujian asumsi klasik untuk memastikan model regresi yang dipakai valid untuk digunakan. Uji asumsi klasik yang akan dilakukan adalah uji normalitas, uji heteroskedastisitas, uji multikollinearitas . Uji normalitas digunakan untuk melihat apakah data yang dikumpulkan terdistribusi normal. Uji heteroskedastisitas dilakukan untuk menguji model regresi terjadi ketidaksamaan varians dari residual. Uji multikollinearitas dilakukan untuk membuktikan apakah dalam model regresi terdapat multikollinearitas. Model perumusa $n$ regresi yang dirumuskan sebagai berikut:

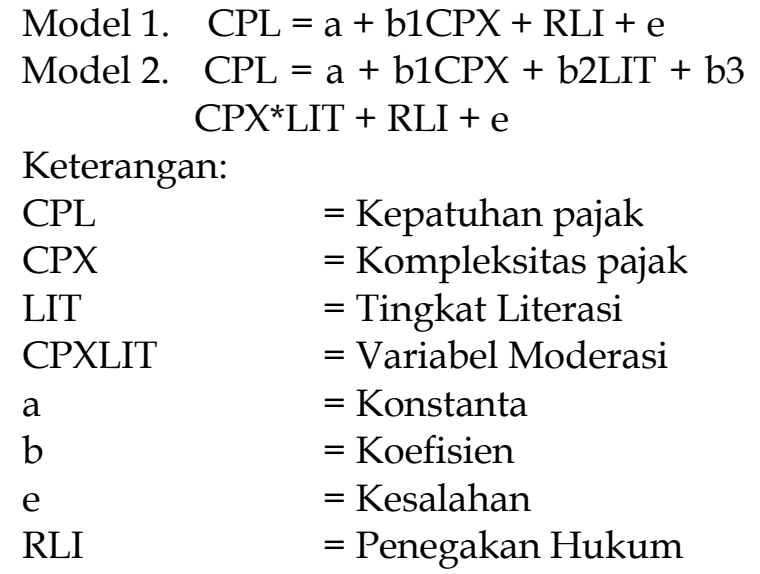

Kompleksitas pajak berpengaruh negatif pada kepatuhan pajak sesuai hipotesis $1(\mathrm{H} 1)$ diterima apabila dalam model 1 tingkat signifikansinya sudah masuk di dalam skala signifikan dan koefisien regresinya (b1) negatif. Hipotesis 2(H2) diterima apabila dalam model 2 tingkat signifikansinya sudah masuk di dalam skala signifikan dan koefisien regresi b3 pada model 2 lebih besar dari koefisien regresi b1 pada model 1 .

\section{Variabel Kontrol}

Variabel kontrol merupakan variabel yang digunakan untuk mengkontrol hubungan kausal supaya mendapatkan model empiris yang lebih lengkap dan baik. Variabel kontrol ditambahkan agar pengaruh variabel bebas terhadap variabel tak bebas tidak dipengaruhi oleh faktor luar yang tidak diteliti sehingga mengurangi kemungkinan adanya hasil perhitungan bias. Variabel kontrol yang ditambahkan dalam penelitian ini adalah demokrasi dan tarif pajak.

\section{Penegakan hukum}

Penelitian ini juga melihat seberapa baik penegakan hukum di suatu negara berdasarkan pada rule of law index (World Justice Project, 2020). Terdapat 4 prinsip yang mendasari rule of law index yaitu akuntabilitas, just laws, pemerintahan yang terbuka, dapat diakses dan penyelesaian sengketa yang tidak memihak. Rule of law terdiri dari beberapa faktor yaitu pembatasan kekuasaan pemerintah, tingkat korupsi, pemerintahan yang terbuka, hak dasar, ketertiban dan keamanan, penegakan peraturan, keadilan sipil, dan peradilan pidana. Jika penegakan hukum disuatu negara baik, maka kepercayaan masyarakat pada pemerinta akan meningkat dan akhirnya dapat meningkatkan kepatuhan pajak (Mas'Ud et al., 2019).

\section{HASIL DAN PEMBAHASAN}

Analisis statistik deskriptif digunakan untuk memberi gambaran secara statistik mengenai variabel yang digunakan dalam penelitian ini. Variabel dependan yang digunakan adalah kepatuhan pajak, variabel 
independen yang digunakan adalah kompleksitas pajak dan variabel moderasi yang digunakan adalah tingkat literasi.

Tabel 2. Statistik deskriptif

\begin{tabular}{lccccc}
\hline & Rerata & Min & Maks & Std. Dev. & Median \\
\hline Kompleksitas Pajak & 0,39 & 0,2 & 0,53 & 0,07 & 0,40 \\
Literasi & 90,34 & 56,44 & 99,82 & 11,33 & 94,58 \\
Kepatuhan Pajak & 0,43 & 0,20 & 0,83 & 0,11 & 0,43 \\
Penegakan Hukum & 0,54 & 0,39 & 0,81 & 0,09 & 0,51 \\
\hline
\end{tabular}

Literasi memiliki rerata 90,34 yang dapat diartikan bahwa rata-rata 90,34\% masyarakat berusia 15 tahun dan lebih pada negara-negara sampel dapat membaca dan menulis pernyataan sederhana. Skor rerata kompleksitas pajak menunjukan nilai 0,39 yang dapat diartikan menurut skala dari (Hoppe et al., 2019) bahwa pada umumnya negara-negara didunia memiliki perpajakan dengan kompleksitas pajak yang sedang. Standar deviasi variabel kompeksitas pajak rendah sehingga variasi kompleksitas pajak antar negara tidak terlalu berbeda. Rerata kepatuhan pajak bernilai 0,43, artinya negara-negara pada sampel memperoleh rata-rata $43 \%$ penghasilan pajak dari potensi pajak yang dapat diterima. Kepatuhan hukum pada negara-negara sampel menunjukan angka rerata 0,54 dari skor penuh 1 sehingga dapat diartikan bahwa tingkat masyarakat patuh pada hukum yang berlaku sedang. Standar deviasi variabel penegakan hukum juga rendah sehingga tidak terdapat perbedaan signifikan antar negara-negara sampel.

Tabel 3. Uji Asumsi Klasik

\begin{tabular}{|c|c|c|}
\hline Asumsi & Pengujian & Simpulan \\
\hline Normalitas & $\begin{array}{l}\text { Komolgorov-Smirnoff } \\
\text { Sign. Model } 1=0,2 \\
\text { Sign. Model } 2=0,2\end{array}$ & $\begin{array}{l}\text { Lolos asumsi } \\
\text { normalitas }\end{array}$ \\
\hline Heteroskedastisitas & $\begin{array}{l}\text { Scaterplot } \\
\text { titik-titik data menyebar di atas dan dibawah } \\
\text { atau disekitar angka dan tidak berkumpul di } \\
\text { atas atau bawah saja. } \\
\text { Penyebaran titik-titik data yang ada pada } \\
\text { gambar } 2 \text { dan } 3 \text { juga tidak membentuk suatu } \\
\text { pola (Ghozali, 2016). }\end{array}$ & $\begin{array}{l}\text { Lolos asumsi } \\
\text { Heteroskedastisitas }\end{array}$ \\
\hline
\end{tabular}




\begin{tabular}{|c|c|c|}
\hline Multikolinearitas & $\begin{array}{lr}\text { Tolerance model 1: } \\
\text { CPX } & =0,99 \\
\text { RLI } & =0,99 \\
\text { VIF model 1= } & \\
\text { CPX } & =1,01 \\
\text { RLI } & =1,01 \\
\text { Tolerance model 2= } & =0,92 \\
\text { CPX } & =0,66 \\
\text { RLI } & =0,66 \\
\text { LIT } & \\
\text { VIF model 2= } & \\
\text { CPX } & =1,06 \\
\text { RLI } & =1,52 \\
\text { LIT } & =1,52\end{array}$ & $\begin{array}{l}\text { Lolos asumsi } \\
\text { Multikolinearitas }\end{array}$ \\
\hline
\end{tabular}

Berdasarkan hasil pengujian asumsi klasik, model data yang digunakan dalam penelitian ini lulus uji normalitas, uji heteroskedastisitas, dan uji multikolinearitas. Model data tersebut dapat digunakan untuk pengujian regresi.

Berdasarkan hasil analis regresi pada model 1 di Tabel 3, tampak bahwa kompleksitas pajak berpengaruh negatif terhadap kepatuhan (pada tingkat signifikansi 10\%). Adapun variabel kontrol dalam model 1 yaitu penegakan hukum juga memiliki pengaruh signifikan. Nilai signifikansi dari variabel kompleksitas adalah 0,091 sehingga lolos dalam skala signifikansi $10 \%$. Koefisien regresi yang dihasilkan adalah -0,156 (negatif) sehingga kompleksitas pajak berpengaruh negatif terhadap kepatuhan pajak. Penegakan hukum juga terbukti dapat menjadi variabel kontrol pada model penelitian ini.

Berdasarkan hasil analis regresi pada model 2 di Tabel 3, tampak bahwa variabel kompleksitas pajak memiliki nilai signifikansi 0,520 sehingga tidak berpengaruh signifikan. Nilai signifikansi dari variabel moderasi adalah 0,286 sehingga tidak lolos dalam skala signifikansi $10 \%$. Koefisien regresi yang dihasilkan adalah 0,579 (positif) dan lebih besar dari koefisien regresi pada model 1. Hasil uji regresi ini menunjukan bahwa literasi tidak dapat menjadi variabel pemoderasi dalam hubungan antara kompleksitas terhadap kepatuhan pajak.

Tabel 4. Uji Hipotesis

\begin{tabular}{clll}
\hline Variabel & Adj. $\mathrm{R}^{2}$ & Koefisien Beta & Sign. \\
\hline Model 1 & 0,092 & & \\
CPX & & $-0,156$ & $0,091^{* *}$ \\
RLI & & 0,350 & $0,030^{*}$ \\
\hline Model 2 & & \\
CPX & 0,076 & 0,250 & 0,520 \\
LIT & & $-0,004$ & 0,341 \\
CPX*LIT & & 0,579 & 0,286 \\
RLI & & 0,380 & $0,062^{* *}$ \\
\hline
\end{tabular}

* Signifikan pada 5\%;

** signifikan pada $10 \%$ 
Regulasi pajak yang kompleks dapat menyebabkan wajib pajak kurang patuh pada regulasi pajak. Hal tersebut terbukti dari uji regresi yang menghasilkan koefisien negatif dan masuk dalam skala signifikansi $10 \%$. Dengan hasil tersebut, maka dapat disimpulkan hipotesis kompleksitas pajak berpengaruh negatif terhadap kepatuhan pajak diterima. Hasil ini selaras dengan beberapa penelitian terdahulu (Gambo et al., 2014; Martins \& Taborda, 2017; Remali et al., 2020). Regulasi yang kompleks menjadikan wajib pajak pada suatu negara sulit paham. Menurut Saad (2014) Kurang pahamnya wajib pajak pada regulasi pajak dapat menyebabkan ketidakpatuhan pada regulasi pajak secara sengaja maupun tidak sengaja.

Wajib pajak yang memiliki pemahaman yang rendah mengenai regulasi pajak cenderung tidak patuh dalam menyelesaikan kewajiban perpajakannya secara sengaja ataupun tidak sengaja. Pada beberapa negara, regulasi pajak menjadi lebih kompleks semenjak kewajiban perpajakan dilakukan sendiri oleh wajib pajak atau self assesstment system (Borrego et al., 2016). Wajib pajak sendiri yang harus melakukan sendiri prosedur pelaporan dan pembayaran pajak. Dengan tuntutan kemandirian untuk melaporkan, tidak semua wajib pajak mengerti apa saja yang perlu dilakukan untuk memenuhi kewajiban perpajakan. Hal tersebut mengakibatkan munculnya pemahaman masing-masing dari wajib pajak, dan timbul ambiguitas mengenai pemahaman regulasi pajak. Ketidakpastian mengenai interpretasi regulasi pajak menyebabkan wajib pajak harus memberikan usaha lebih untuk memahami dan melakukan kewajiban perpajakan sesuai regulasi yang berlaku. Kemampuan wajib pajak dalam memahami dan memberikan effort untuk memenuhi kewajiban perpajakan juga berbeda-beda sehingga sulit agar semua wajib pajak patuh.

Literasi tidak mampu dalam memoderasi pengaruh negatif dari kompleksitas pajak pada kepatuhan pajak. Berdasarkan uji regresi, variabel moderasi memiliki nilai signifikansi sebesar 0,286 sehingga tidak signifikan walaupun koefisien regresinya lebih besar dari model 1 yaitu 0,579 . Dengan hasil tersebut maka hipotesis tingkat literasi memperlemah pengaruh kompleksitas pajak terhadap kepatuhan pajak ditolak. Proses memahami regulasi pajak yang kompleks tidak hanya membutuhkan kemampuan literasi, namun pengetahuan mengenai pajak juga diperlukan. Penelitian di Canada menghasilkan bahwa kemampuan literasi dan pengetahuan dasar mengenai pajak saja belum cukup untuk memahami dan melaksanakan regulasi pajak yang kompleks (Pham et al., 2021).

Kompleksitas pajak memiliki 2 komponen utama dalam penentuannya yaitu, tax code complexity dan tax framework complexity (Hoppe et al., 2018). Tax code complexity membahas mengenai detail regulasi pajak, ambiguitas dan interpretasi dari regulasi tersebut, perubahan, dan juga perhitungan dari pajak itu sendiri terkhusus pada regulasi pajak pendapatan badan. Beberapa detail tersebut merupakan sebagian kecil dari komponen tax code complexity seperti kebijakan perpajakan yang berkaitan dengan dividen, investasi, dan juga manajemen pajak. Sedangkan tax framework complexity membahas bagaimana kompleksitas dalam mengisi SPT, tata cara, dan juga prosedur audit dalam perpajakan. Dengan berbagai komponen kompleksitas tersebut maka peran literasi hanya dapat mencakup sebagian kecil dalam memahami kompleksitas pajak seperti detail dari regulasi pajak maupun komponen ambiguitas dan interpretasi.

\section{SIMPULAN}

Berdasarkan hasil uji hipotesis maka dapat disimpulkan bahwa kompleksitas pajak berpengaruh negatif pada kepatuhan pajak. Penelitian ini juga menemukan bahwa literasi tidak dapat memperlemah efek negatif kompleksitas pajak pada kepatuhan pajak.

Penelitian ini mengambil sampel 
sebanyak 52 negara dari total 192 negara menurut $\mathrm{PBB}$, sehingga dengan kata lain hasil penelitian ini kurang representatif bagi seluruh negara di dunia. Pembaca perlu berhati-hati dalam menggeneralisasikan hasil penelitian ini dalam seting global. Kompleksitas pajak memiliki beberapa komponen seperti, kompleksitas peraturan pajak dan sitem pelaporan pajak serta berbagai komponen lagi di dalamnya. Peran literasi tidak mampu mengantisipasi semua komponen kompleksitas pajak tersebut.

Penelitian ini secara teoritis memberikan temuan bahwa kompleksitas pajak berpengaruh negatif paja kepatuhan pajak, dimana didukung oleh penelitian sebelumnya oleh Gambo et al. (2014), Martins dan Taborda (2017), dan Remali et al. (2020). Pada penelitian ini ditambahkan literasi sebagai variabel moderasi yang ternyata tidak dapat memperlemah pengaruh negatif kompleksitas pajak terhadap kepatuhan

\section{REFERENSI}

Alhempi, R. R., Ardiansyah, I., Kusumastuti, S. Y., \& Endri, E. (2020). Tax compliance in income tax payments. International Journal of Innovation, Creativity and Change, 13(1), 356-374.

Alm, J., Liu, Y., \& Zhang, K. (2019). Financial constraints and firm tax evasion. International Tax and Public Finance, 26(1), 71-102.

https://doi.org/10.1007/s10797-0189502-7

Borrego, A. C., Lopes, C. M. M., \& Ferreira, C. M. S. (2016). Tax complexity indices and their relation with tax noncompliance: Empirical evidence from the Portuguese tax professionals. Tékhne, 14(1), 20-30. https://doi.org/10.1016/j.tekhne.2016. 07.003

Budak, T., \& James, S. (2018). The level of tax complexity: A comparative analysis between the UK and Turkey based on the OTS Index. February, 27-40.

Collier, R., Kari, S., Ropponen, O., Simmler, M., Todtenhaupt, M., \& Vol, S. (2018). EconPol POLICY REPORT Dissecting the pajak. Agar kepatuhan pajak meningkat dan pendapatan pajak bertambah, pemerintah perlu mempertimbangkan regulasi perpajakan yang berlaku seperti tata cara pelaporan dan pembayaran pajak. Memberikan sosialisasi secara berkala kepada wajib pajak mengenai regulasi yang berlaku dapat meningkatkan pemahaman wajib pajak sehingga risiko ketidakpahaman dapat berkurang.

Penelitian selanjutnya diharapkan dapat lebih fokus meneliti kompleksitas pajak pada kawasan negara tertentu seperti contohnya asia tenggara dengan ruang lingkup lebih fokus lagi pada transfer pricing dikarenakan merupakan kebijakan paling kompleks (Hoppe et al., 2020). Dengan ruang lingkup yang lebih sempit, kualitas penelitian nantinya akan dapat mewakili populasi yang diteliti.

EU's Recent Anti-Tax Avoidance Measures: Merits and Problems Dissecting the EU's Recent Anti-Tax Avoidance Measures: Merits and Problems. 2. www.econpol.eu

Dover, R., Ferret, B., Gravino, D., Jones, E., \& Merler, S. (2015). Assessment of the magnitude of aggressive corporate tax planning. In Bringing transparency, coordination and convergence to corporate tax policies in the European Union (Issue September).

Dwenger, N., Kleven, H., Rasul, I., \& Rincke, J. (2014). Extrinsic vs Intrinsic Motivations for Tax Compliance. Evidence from a Randomized Field Experiment in Germany. Conference Paper.

Gambo, E., Masud, A., Mustapha, N., \& Oginni, S. (2014). Tax complexity and tax compliance in African self-assessment environment. International Journal of Management Research \& Review, 4(5), 575583.

Gerger, G. Ç., Türegün, F. B., \& Gerçek, A. (2019). The importance of tax literacy in tax compliance, suggestions to be developed in the case of country. 209-215. 
https://doi.org/10.26650/PB/SS10.201 9.001.032

Ghozali, I. (2016). Ghozali, Imam. 2016. Aplikasi Analisis Multivariate dengan Program SPSS. Semarang: Badan Penerbit UNDIP. Analisis Multivariate Dengan Program SPSS.

Hallsworth, M. (2014). The use of field experiments to increase tax compliance. Oxford Review of Economic Policy, 30(4), 658-679.

https://doi.org/10.1093/oxrep/gru034

Hamid, N. A., Noor, R. M., Zam, Z. M., Hussin, N., \& Dangi, M. R. M. (2018). Factors Affecting Tax Compliance Among Micro Businesses in Malaysia. Advanced Science Letters, 24(4), 26462650.

https://doi.org/10.1166/asl.2018.11025

Hoppe, T., Deborah, S., Schipp, A., \& Siegel, F. (2018). 2018 Global MNC Tax Complexity Survey. شماره 8 ; ص 117-99. https://www.researchgate.net/publica tion/336533269_Measuring_Tax_Compl exity_Across_Countries_A_Survey_Stu dy_on_MNCs

Hoppe, T., Schanz, D., Sturm, S., \& SurethSloane, C. (2018). What are the drivers of tax complexity for MNCs? Global evidence. Intertax, 46(8-9), 654-675.

Hoppe, T., Schanz, D., Sturm, S., \& SurethSloane, C. (2019). Measuring Tax Complexity Across Countries: A Survey Study on MNCs. SSRN Electronic Journal, September 2020. https://doi.org/10.2139/ssrn.3469663

Isa, K. (2014). Tax complexities in the Malaysian corporate tax system: Minimise to maximise. International Journal of Law and Management, 56(1), 5065. https://doi.org/10.1108/IJLMA-082013-0036

Kamleitner, B., Korunka, C., \& Kirchler, E. (2012). Tax compliance of small business owners: A review. International Journal of Entrepreneurial Behaviour and Research, 18(3), 330-351. https://doi.org/10.1108/135525512112 27710
Lignier, Philip and Evans, C. (2012). LignierEvans_TheRiseAndRiseOfTaxComp lianceCostsForTheSmallBusinessSectorInA ustralia.pdf. April.

Martinez, A. L., \& da Silva, R. (2019). Tax Law Readability and Tax Complexity. SSRN Electronic Journal, 1-21. https:// doi.org/10.2139/ssrn.3440547

Martins, A., \& Taborda, D. (2017). The purpose of tax law: A perspective on financial instruments' fair value adjustments in Portugal. EJournal of Tax Research, 15(3), 387-401.

Mas'Ud, A., Manaf, N. A. A., \& Saad, N. (2019). Trust and power as predictors to tax compliance: Global evidence. Economics and Sociology, 12(2), 192-204. https:// doi.org/10.14254/2071789X.2019/12-2/11

Mascagni, G., Monkam, N., \& Nell, C. (2018). Unlocking the Potential of Administrative Data in Africa: Tax Compliance and Progressivity in Rwanda. In SSRN Electronic Journal (Issue October). https:// doi.org/10.2139/ssrn.3120309

Mawejje, J., \& Sebudde, R. K. (2019). Tax revenue potential and effort: Worldwide estimates using a new dataset. Economic Analysis and Policy, 63, 119-129. https:// doi.org/10.1016/j.eap.2019.05.0 05

Montoya, S. (2018). Defining literacy. In GAML Fifth Meeting, 17-18. https:// doi.org/10.1177/002248710005 1004003

Mutascu, M., \& Danuletiu, D. (2013). The literacy impact on tax revenues. Economics Discussion Papers, 63, 0-25.

Neve, J. De, \& Imbert, C. (2019). How to Improve Tax Compliance? Evidence from Population-wide Experiments in Belgium Maarten Luts. CEP Discussion Paper, 1621.

Nichita, A. (2015). Knowledge Is Power. Improving Tax Compliance By Means of Boosting Tax Literacy. Annals of the University of Oradea - Economic Science, 1(1), 770-774. 
Nichita, A., Batrancea, L., Marcel Pop, C., Batrancea, I., Morar, I. D., Masca, E., Roux-Cesar, A. M., Forte, D., Formigoni, H., \& da Silva, A. A. (2019). We Learn Not for School but for Life: Empirical Evidence of the Impact of Tax Literacy on Tax Compliance. Eastern European Economics, 57(5), 397-429. https://doi.org/10.1080/00128775.2019 .1621183

Oladipupo, A. O., \& Obazee, U. (2016). Tax Knowledge, Penalties and Tax Compliance in Small and Medium Scale Enterprises in Nigeria. IBusiness, 08(01), 1-9.

https://doi.org/10.4236/ib.2016.81001

Palil, M. R., \& Mustapha, A. F. (2011). Factors affecting tax compliance behaviour in self assessment system. African Journal of Business Management, 5(33), 1286412872.

https://doi.org/10.5897/ajbm11.1742

Palil, M. R., \& Rusyidi, M. A. (2013). The Perception of Tax Payers on Tax Knowledge and Tax Education with Level of Tax Compliance: A Study the Influences of Religiosity. ASEAN Journal of Economics, Management and Accounting, 1(1), 118-129.

Pham, A., Genest-Grégoire, A., Godbout, L., \& Guay, J.-H. (2021). Tax Literacy: A Canadian Perspective. Canadian Tax Journal/Revue Fiscale Canadienne, 68(4), 987-1007.

https://doi.org/10.32721/ctj.2020.68.4. pham

Remali, A. M., Khairah, R., Nordin, N. K., Hamdan, N. A., \& Lutfi, N. I. A. (2020). Tax Compliance: Taxpayers' View (Perception). Global Business and Management Research: An International Journal, 12(4), 189-200. www.economicshelp.org

Roser, M., \& Ortiz-Ospina, E. (2018). Literacy. https://ourworldindata.org/literacy

Saad, N. (2014). Tax Knowledge, Tax Complexity and Tax Compliance: Taxpayers' View. Procedia - Social and Behavioral Sciences, 109(1), 1069-1075. https:// doi.org/10.1016/j.sbspro.2013.1 2.590

Sebele-mpofu, F. Y., \& Chinoda, T. (2019). Tax Knowledge , Tax System Complexity Perceptions and Attitudes of the Commercial Sugarcane Farmers and Their Influence on Tax Compliance in the Lowveld Area, Zimbabwe. International Journal of Innovative Science and Research Technology, 4(4), 407-418.

Swapna, G., \& Biradar, B. S. (2017). Assessment of Information Literacy Skills among Science-Post Graduate Students in Universities of Karnataka State: A Study. Library Herald, 55(4), 581. https:// doi.org/10.5958/09762469.2017.00044.6

Taing, H. B., \& Chang, Y. (2021). Determinants of Tax Compliance Intention: Focus on the Theory of Planned Behavior. International Journal of Public Administration, 44(1), 62-73. https:// doi.org/10.1080/01900692.2020 .1728313

Vishnevsky, V. P., \& Chekina, V. D. (2018). Robot vs. tax inspector or how the fourth industrial revolution will change the tax system: a review of problems and solutions. Journal of Tax Reform, 4(1), 626.

https://doi.org/10.15826/jtr.2018.4.1.0 42

Whitmore, A. (2020). A Comparison of Obesity and Nutrition in Chile and Peru between the Years of 2000-2016.

World Justice Project. (2020). Rule of Law Index Rule of Law Index. In The World Justice Project (Issue June). http://www.oecd.org/mena/governan ce/45447873.pdf

WorldoMeter. (2018). WorldoMeter: Real Time World Statistics. Population by Country. WorldoMeter. 